\title{
Teaching Randomness Using Coins and Dice
}

\author{
George Petrakos \\ Dept. of Public Administration, Panteion University \\ 136 Syngrou Ave., 17671, Athens, Greece \\ Tel: 30-210-920-1637 E-mail: petrakos@panteion.gr
}

Received: August 7, 2014 Accepted: August 25, 2014 Published: August 25, 2014

doi:10.5296/jse.v4i3.6091 URL: http://dx.doi.org/10.5296/jse.v4i3.6091

\begin{abstract}
This article describes some easy to perfom random experiments for randomly selecting items and producing random numbers, all by using coins and dice. The aim is to illustrate basic concepts, as radomness and symmetry in teaching probability theory and practice.
\end{abstract}

Keywords: Random experiment, Randomness, Symmetry, Sample space, Random number generator 


\section{Introduction}

Students intuition and perspective regarding randomness and symmetry of random experiments has been thoroughly studied in the literature of educational statistics (Green,1997; Truran, 1985; Batanero et al, 2004), providing interesting - and sometimes unexpected- results and guidelines. Random experiments which are easy to perform using coins and dice can provide us with a tool of selecting one item out of $s(s<n)$ with equal probabilities assigned. By repeating these experiments $r$ times, we can select $r(r<s)$ items from s, either with replacement or without. Futhermore, we can use these experiments to construct a simple random number generator assuming discrete uniform distribution. The underlying method is demonstrated through typical statistical examples-exercises.

\section{The example}

There are many everyday life instances where we have to make a fair choice among several items. Here is such an example:

- For the last question of a multiple choice test in statistics, Mary decides to use a die in order to select one of the five(5) possible answers. She does not have any clue, so she assumes that all answers are equally likely to be correct. If the outcome is 1-5, she selects the corresponding answer, while if the outcome is 6 , she rolls the die again until a number from 1-5 appears.

The question is: will that experiment produce 5 equally likely outcomes? Intuitively, because of the symmetry of the process, we think it will. But it is not difficult to prove and also generalize this statement. Here it is:

Let us examine the probabilities of choosing each of the five possible answers. The probability to choose the first answer $\mathrm{P}\left(\mathrm{A}_{1}\right)$ can be calculated from the following events

$\mathrm{A}_{1}^{1}=\{$ one in the first trial $\}$

$\mathrm{A}_{1}^{2}=\{$ six in the first trial and one in the second $\}$,

$\mathrm{A}_{1}^{3}=\{$ six in the first and the second trial and one in the third $\}$,

as follows:

$$
\begin{aligned}
P\left(\mathrm{~A}_{1}\right) & =P\left(\mathrm{~A}_{1}^{1} \cup \mathrm{A}_{1}^{2} \cup \mathrm{A}_{1}^{3} \cup \ldots\right)=P\left(\mathrm{~A}_{1}^{1}\right)+P\left(\mathrm{~A}_{1}^{2}\right)+P\left(\mathrm{~A}_{1}^{3}\right)+\ldots \\
& =\frac{1}{6}+\frac{1}{6} \cdot \frac{1}{6}+\frac{1}{6} \cdot \frac{1}{6} \cdot \frac{1}{6}+\ldots=\sum_{k=0}^{\infty} \frac{1}{6} \cdot\left(\frac{1}{6}\right)^{k} .
\end{aligned}
$$

Since this is the sum of a geometrical progression starting from $1 / 6$ with step equal to $1 / 6$, the result is: 


$$
P\left(\mathrm{~A}_{1}\right)=\frac{1 / 6}{1-(1 / 6)}=\frac{1}{5}
$$

In a similar manner we can show that $\mathrm{P}\left(\mathrm{A}_{2}\right)=\mathrm{P}\left(\mathrm{A}_{3}\right)=\mathrm{P}\left(\mathrm{A}_{4}\right)=\mathrm{P}\left(\mathrm{A}_{5}\right)=1 / 5$.

What if the choices are 4 ?

The events that will make her choose the first answer are:

$\mathrm{A}_{1}^{1}=\{$ one in the first trial $\}$,

$\mathrm{A}_{1}^{2}=\{$ five or six in the first trial and one in the second $\}$,

$\mathrm{A}_{1}^{3}=\{$ five or six in the first and the second trial and one in the third $\}$

the relevant probability:

$$
\begin{aligned}
P\left(\mathrm{~A}_{1}\right) & =P\left(\mathrm{~A}_{1}^{1} \cup \mathrm{A}_{1}^{2} \cup \mathrm{A}_{1}^{3} \cup \ldots\right)=P\left(\mathrm{~A}_{1}^{1}\right)+P\left(\mathrm{~A}_{1}^{2}\right)+P\left(\mathrm{~A}_{1}^{3}\right)+\ldots \\
& =\frac{1}{6}+\frac{2}{6} \cdot \frac{1}{6}+\frac{2}{6} \cdot \frac{2}{6} \cdot \frac{1}{6}+\ldots=\sum_{k=0}^{\infty} \frac{1}{6} \cdot\left(\frac{2}{6}\right)^{k}=\frac{1 / 6}{1-(2 / 6)}=1 / 4
\end{aligned}
$$

and by symmetry, $\mathrm{P}\left(\mathrm{A}_{2}\right)=\mathrm{P}\left(\mathrm{A}_{3}\right)=\mathrm{P}\left(\mathrm{A}_{4}\right)=\mathrm{P}\left(\mathrm{A}_{5}\right)=1 / 4$.

We can easily generalize the above results when we want to choose one element out of $\mathrm{s}$ using a random experiment with $\mathrm{n}(\mathrm{n}>\mathrm{s})$ equally likely outcomes. If the result is from 1 to $\mathrm{s}$, we choose the corresponding element, otherwise we repeat the experiment until so. The final probability of choosing any element $\mathrm{i}$ between 1 and $\mathrm{s}$ is:

$$
P\left(A_{i}\right)=\frac{1}{n}+\frac{n-s}{n} \cdot \frac{1}{n}+\left(\frac{n-s}{n}\right)^{2} \frac{1}{n}+\ldots=\frac{\frac{1}{n}}{1-\frac{n-s}{n}}=\frac{\frac{1}{n}}{\frac{s}{n}}=\frac{1}{s}
$$

So again the probability of all choices is the same and is equal to one over the number of choices. This result is independent from the number $\mathrm{n}$ of outcomes of the random experiment. In general, to speed up the procedure, we must choose-design an experiment with $\mathrm{n}$ as close as possible to $\mathrm{s}$ (but always $\mathrm{n} \geq \mathrm{s}$ ). To evaluate this we should consider that by using $\mathrm{x}$ coins and $\mathrm{y}$ dice we perform an experiment with $\mathrm{n}=2^{\mathrm{x}} \cdot 6^{\mathrm{y}}$, were $\mathrm{x}, \mathrm{y}$ are natural numbers.

\section{The experiment}

Let us now summarize some experiments with a different number of outcomes, using coins and dice that can evaluate this process: 


\begin{tabular}{|c|c|c|}
\hline One coin & ale & 2 outcomes \\
\hline Two coins & & 4 outcomes \\
\hline One die & & 6 outcomes \\
\hline Three coins & & 8 outcomes \\
\hline One die and one coin & & $6 \times 2=12$ outcomes \\
\hline Four coins & & 16 outcomes \\
\hline One die and two coins & & $6 \times 4=24$ outcomes \\
\hline Five coins & & 32 outcomes \\
\hline Two dice & & 36 outcomes \\
\hline
\end{tabular}

\section{Generating Random Numbers}

You may have to select at random one out of ten classmates. First, you assign numbers from 1-10 to your classmates and then you roll a die and flip a coin. If the outcome is HEADS you add 0 to the die result and if it is TAILS you add 6 to the die result, producing the following sample space $\Omega$ (set of all possible outcomes): $\Omega=\{1,2,3,4,5,6,7,8,9,10,11,12\}$. If the result is $1-10$, then you select the corresponding person, otherwise you repeat the experiment. You have 10/12 (about 83\%) probability to complete the experiment in the first trial and only $2,7 \%$ probability to try more than twice. For an extended list and descriptions of similar experiments see Shapiro, 2005.

This process can be used in order to select any $r$ elements from $s$, either with replacement or without. So we can easily construct (randomly) a 3-digit number using one die and one coin, three times, as follows:

- choosing a number from 1-9 for the $1^{\text {st }}$ digit (zero is not considered as first digit)

- choosing a number from 1-10 for the $2^{\text {nd }}$ digit (number 10 corresponds to digit 0 )

- choosing a number from 1-10 for the $3^{\text {rd }}$ digit (number 10 corresponds to digit 0 )

For another case, suppose we want to generate a random number from 1 to 500 . We roll a die once for the first digit and code results as follows: 


\section{\begin{tabular}{l|llllll} 
DICE OUTCOME & 1 & 2 & 3 & 4 & 5 & 6
\end{tabular} \\ \begin{tabular}{l|llllll} 
FIRST DIGIT & 1 & 2 & 3 & 4 & 0 & Roll again
\end{tabular}}

For the second and third digit, we roll a die and flip a coin, as we did with the 3-digit example before. This experiment produces a number from 000 to 499 . We conclude the process by associating result 000 to number 500 .

\section{References}

Batanero, C., Godino, J. D., \& Roa, R. (2004). Training Teachers to Teach Probability. $\begin{array}{llll}\text { Journal of Statistics } & \text { Education, }\end{array}$ http://www.amstat.org/publications/jse/v12n1/batanero.html

Green, D.R. (1997). Recognising Randomness. Teaching Statistics, 19(2), 36-39. http://dx.doi.org/10.1111/j.1467-9639.1997.tb00324.x

Shapiro, D. (2005). Dice Fest. The Games Journal, A Magazine about Board games. http://www.thegamesjournal.com/articles/DiceFest.shtml.

Truran, J. (1985). Children's Understanding of Symmetry. Teaching Statistics, 7(3), 69-74. http://dx.doi.org/10.1111/j.1467-9639.1985.tb00588.x 